\title{
Current Issues in Succession Law
}

As a series of essays rather than a work composed by a single author, Current Issues in Succession Law is able to present a number of different points of view on a diverse range of topics. While all are connected by the central theme of the law of succession, each chapter investigates an individual issue in impressive detail, providing a thorough compendium for anyone interested in, or associated with, this area of law. Although the vast majority of the authors are academics, including such heavyweights as Professor Lionel Smith, there is also a welcome contribution from practitioners with experience of handling such matters in real world situations. The relevance of this work to the current law of succession cannot be overemphasised and, despite its accessible size and small stature, is a compilation of the highest standard.

As a collection of individual papers, there is always the risk that such a work will present itself more as a Frankenstein's creature, a whole grafted together from a disparate collection of assorted parts. While this is true in one respect (the editors, like Dr Frankenstein, chose the best components available rather than one imperfect whole), Current Issues in Succession Law never comes across as anything other than a cohesive legal text. Much credit must be given to the editors for this accomplishment, but it also speaks to the consistent high-standards of the contributing authors.

It would be an exaggeration to label the order of chapters in Current Issues in Succession Law intuitive. Nevertheless, the contents are arranged in a sensible fashion with the added bonus that the material is presented in such a way that it never becomes monotonous. The chapters are manageable to even a novice in this field. They are concise without being superficial and yet detailed enough to cover all necessary legal questions. The natural breaks between chapters prevents the reader from becoming either complacent or numb, with new topics constantly arising to refresh interest and keep the mind keen. Each of the chapters wonderfully synthesises a complex and disparate history of both statute and case law related to its respective issue. Even for those with experience of succession law, this work will promote new avenues of thought and raise questions that have probably never even been considered.

While Current Issues in Succession Law could hardly be considered essential reading for all academics and practitioners, it certainly achieves that status for anyone connected to either the teaching or practice of wills and probate. With respect to those associated in any with estate planning, it could easily be categorised as indispensable. By spotting and dealing with the modern problems and issues related to the law of succession, a diligent reading of this book will help to avoid potential pitfalls and identify deficiencies in existing testamentary instruments. From a practical perspective, this is one of its greatest strengths.

One of the most attractive aspects to this book, approaching it as I do from an academic standpoint, is the gravitas of its contributing authors. From a property law perspective it is an impressive line-up and one that inspires great confidence in the material contained within. Furthermore, the academic experience of the authors in this field adds clarity to what would otherwise be an extremely confusing area of law. Current Issues in Succession Law is written to be read easily, its material designed to be readily synthesised and absorbed by its reader. 
Having talked about the general characteristics of the book, it is worth considering some of its individual chapters in more detail, although it is unfortunately not possible to do justice to all of them in so limited a forum as a book review.

The first chapter is sensibly placed and acts almost as a prologue to the work as a whole, helping to put this area of law into context for any reader (including myself) not altogether familiar with its details and innate intricacies. This is one of the ways that the book makes itself so accessible to readers from all backgrounds in law. Its author, Roger Kerridge, explains the reforms undertaken with the entry into force of the Inheritance and Trustees' Powers Act 2014, a statute influenced by the Law Commission through several Reports. Rather than presupposing knowledge of this area of succession law, however, Kerridge delves into the background to the statute and the issues that it sought to address, whether, in his opinion, successfully or not. He examines the law as it has developed and the recommendations made by previous Law Commission Reports and statutes. This approach helps the reader build up a good base of knowledge and also appreciate why this area of law has been in need of change on so frequent a basis. Breaking away from purely academic support and criticism, Kerridge also examines questions that are relevant for practitioners, reflecting the dual-use nature of this book. It is never intended to be solely for either academics or practitioners; like its cadre of contributing authors, it encapsulates both fields.

The second chapter, while again appealing to both practitioners and academics, also operates as something of a cautionary tale to anyone thinking of creating instruments to deal with their property after they have died. With the rise in testamentary documents created without the benefit of legal advice, this chapter is well worth a read by all prospective testamentary instrument writers. In particular, it deals with the various avenues that may be used to challenge testamentary dispositions. In a similar respect, chapter seven deals with legal capacity for creating testamentary instruments, together with related issues such as want of knowledge and approval. From personal experience, these are extremely salient topics and are often the basis of questions from both students and prospective will makers alike. Such things are not usually covered by a conventional survey course on property law and are an extremely welcome addition. Such things are not easily explained when raised informally in a classroom or client meeting and I would certainly suggest that anyone with questions on these issues should read these chapters.

Chapter six is composed by one of the editors, Birke Häcker, a Senior Research Fellow at the Max Planck Institute for Tax Law and Public Finance in Munich. While this by itself is unremarkable beyond the author's impressive credentials, one aspect of real benefit is the presentation of a contrasting viewpoint on this area from a Civil Law perspective. This is, I feel, an extremely useful comparison and helps to put into context many of the issues that we deal with in our own jurisdiction. In addition, this chapter also offers an insight into how wills may be interpreted once their creator has passed away and answers key questions that many people have not even thought of asking. It is often taken for granted that one's wishes will simply be carried through or that if a solicitor is employed, a testamentary document shall be watertight. This chapter helps to remedy these misconceptions (undoubtedly to the dismay of many readers) and also provides valuable advice on how to avoid such problems. The practical manner in which a testamentary document is analysed, interpreted, and, potentially, rectified is discussed admirably. 
As a final example, the last chapter seems apt. Composed by one of the practitioner contributors, Emma Chamberlain, its title is forthright and to the point: Estate Planning for Businesses. Far less academic in its approach (and rightfully so), this chapter is an excellent guide on the basic principles surrounding estates and their administration from a more corporate viewpoint. Delving into such issues as taxation and subsequent liability, it is a worthwhile addition to a work focused largely upon academic contemplation and argument. While a potentially dry subject for many, it is an admirable addition to Current Issues in Succession Law if only for its practical application, brevity, and accessibility.

While it would be ideal to look at every chapter, it is simply not possible to do so here and justice could certainly not be done to the contributors if it was attempted. Hopefully the limited examination presented above will whet any potential reader's appetite for a greater helping of the law of succession. It is, at the very least, a work worthy of digestion by any student of the law or prospective creator of a testamentary disposition. Even outside the confines of property law, its practical scope and universal application (everyone dies, after all, and will have some wishes as to the disposition of their property) makes it a worthy read. Put simply, this is one not to be missed.

Matthew E Carn

06 March 2017 